\title{
Frontalis Suspension dengan Fascia Lata pada Ptosis Kongenital
}

Desty Ria Tiffani ${ }^{1}$, Hendriati $^{2}$

\begin{abstract}
Abstrak
Ptosis atau blefaroptosis merupakan kondisi turunnya atau inferodisplacement palpebra superior. Ptosis unilateral dengan fungsi levator yang buruk merupakan kasus yang cukup sulit untuk ditalaksana karena kemungkinan didapatkan hasil akhir yang asimetris. Frontalis suspension dengan fascia lata merupakan salah satu prosedur pilihan untuk ptosis dengan fungsi levator yang buruk. Dilaporkan outcome ptosis kongenital unilateral yang ditatalaksana dengan frontalis suspension dengan fascia lata. Seorang pasien perempuan berusia 24 tahun dengan kelopak atas mata kiri turun sejak lahir dan dirasakan sama sepanjang waktu. Tajam penglihatan kedua mata dalam batas normal. Pada pemeriksaan palpebra mata kiri didapatkan margin reflex distance 1 (MRD1) $2 \mathrm{~mm}$, MRD2 sebesar $5 \mathrm{~mm}$ dan fisura palpebra vertikal (FPV) $7 \mathrm{~mm}$ (FPV mata kanan $11 \mathrm{~mm}$ ). Fungsi levator palpebra mata kiri $4 \mathrm{~mm}$ dan eyelid crease tidak terbentuk. Pada pasien ini dilakukan prosedur repair ptosis dengan teknik frontalis suspension dengan fascia lata. Pada follow up post operasi, terdapat perbaikan secara kosmetik dimana setelah 1 bulan didapatkan peningkatan MRD1 mata kiri menjadi $3 \mathrm{~mm}$. Pada follow up 3 bulan, didapatkan MRD1 mata kiri meningkat menjadi 4 mm sehingga FPV mata kiri meningkat menjadi $9 \mathrm{~mm}$. Kondisi ini dapat menurunkan asimetrisitas FPV kedua mata sehingga secara kosmetik dapat diterima oleh pasien. Komplikasi yang ditemukan adalah lagoftalmus sebesar $1 \mathrm{~mm}$ setelah 3 bulan post operasi. Kesimpulan dari laporan kasus ini adalah frontalis suspension dengan fascia lata pada ptosis kongenital unilateral secara kosmetik memberikan outcome yang baik.
\end{abstract}

Kata kunci: ptosis kongenital, frontalis suspension, fascia lata, levator palpebra, levator aponeurosis

\section{Abstract}

Ptosis or blepharoptosis is a drooping or inferodisplacement of the upper eyelid. Unilateral ptosis with poor levator function is difficult to manage due to asymetrical outcome likely obtained. Frontalis suspension using fascia lata is one of the option for ptosis with poor levator function. Reported an outcome of congenital ptosis repaired with frontalis suspension using fascia lata. A twenty four years old woman with dropping of uper eyelid since birth and present all the time. Visual acquity of both eyes is within normal limit. Left palpebral examination showed margin reflexl distance 1 (MRD1) and MRD2 of $2 \mathrm{~mm}$ and $5 \mathrm{~mm}$, respectively, and $7 \mathrm{~mm}$ of vertical palpebral fissure (VPF). Levator function of left eye decreased to $4 \mathrm{~mm}$ and eyelid crease was not present. Ptosis was repaired with frontalis suspension procedure using fascia lata. During follow-up, there is an improvement in this patient, where after 1 month postoperatively MRD1 of left eye increased to $3 \mathrm{~mm}$. At 3 months follow-up, MRD1 of left eye increased to $4 \mathrm{~mm}$ so that the left eye FPV increased to $9 \mathrm{~mm}$. This condition reduced the FPV asymmetry of both eyes so cosmetically it was more acceptable for the patient. Postoperative complication found in this patient was lagophthalmos of $1 \mathrm{~mm}$ after 3 months postoperatively. The conclusion of this case is frontalis suspension using fascia lata in treating unilateral congenital ptosis gives cosmetically more acceptable outcome.

Keywords: congenital ptosis, frontalis suspension, fascia lata, levator palpebrae

Affiliasi penulis: 1. Program Pendidikan Dokter Spesialis-1 IImu Kesehatan Mata Fakultas Kedokteran Universitas Andalas Padang (FK Unand), 2. Bagian IImu Kesehatan Mata FK Unand.

Korespondensi: irin970@yahool.com, Telp: 08116687349

\section{PENDAHULUAN}

Ptosis atau blefaroptosis merupakan kondisi turunnya atau inferodisplacement palpebra superior. Berdasarkan onsetnya, ptosis dibagi menjadi ptosis kongenital dan ptosis didapat. Ptosis juga dapat 
dikelompokkan berdasarkan etiologinya menjadi miogenik, aponeurotik, neurogenik, mekanik, dan traumatik. Ptosis kongenital sebagian besar terjadi akibat kelainan perkembangan otot levator (miogenik), sedangkan ptosis didapat sering disebabkan oleh tarikan atau disinsersi dari levator aponeurosis (aponeurotik). ${ }^{1,2}$

Repair ptosis merupakan prosedur surgikal okuloplastik yang membutuhkan diagnosis dan perencanaan yang tepat serta pemahaman mengenai anatomi palpebra dan teknik operasi yang baik. Keluhan pasien, riwayat medis dan riwayat operasi akan membantu dalam menentukan apakah repair surgikal diperlukan untuk pasien tersebut. Dari segi fungsional, repair ptosis bertujuan untuk elevasi margo palpebra diatas aksis pupil sehingga meningkatan lapangan pandang superior. ${ }^{1}$ Dari segi kosmetik, repair ptosis bertujuan untuk mencapai kurvatura margo palpebra yang normal, tinggi margo palpebra yang simetris, dan alis mata yang simetris. ${ }^{3}$

Salah satu prosedur surgikal yang sering dilakukan pada ptosis kongenital adalah frontalis suspension. Frontalis suspension merupakan pilihhan utama pada ptosis dengan fungsi levator palpebra yang buruk, yaitu $4 \mathrm{~mm}$ atau kurang. ${ }^{1}$ Aksi otot frontalis normal dihubungkan secara langsung ke palpebra superior dengan menggunakan material suspensi baik yang bersifat autogenous maupun nonautogenous. Autograft seperti fascia lata biasanya merupakan pilihan utama untuk menghindari terjadinya respon antibodi. ${ }^{3}$

Ptosis unilateral dengan fungsi levator yang buruk merupakan kasus yang cukup sulit untuk ditalaksana karena kemungkinan didapatkan hasil akhir yang asimetris. ${ }^{3,4}$

\section{KASUS}

Seorang pasien perempuan berusia 24 tahun dengan keluhan kelopak atas mata kiri turun sejak lahir dan dirasakan sama sepanjang waktu (Gambar 1). Tajam penglihatan kedua mata dalam batas normal yaitu 20/20. Pada pemeriksaan palpebra mata kiri didapatkan margin limbal distance 1 (MRD1) $2 \mathrm{~mm}$, MRD 2 sebesar $5 \mathrm{~mm}$, sedangkan pada mata kanan didapatkan MRD1 dan MRD2 masing-masing $5 \mathrm{~mm}$. Fisura palpebra vertikal (FPV) $7 \mathrm{~mm}$ dan FPV mata kanan $11 \mathrm{~mm}$. Fungsi levator palpebra mata kiri menurun yaitu $4 \mathrm{~mm}$ (gambar 2) dan terdapat lid lag. Eyelid crease tidak terbentuk pada palpebra mata kiri dan Bell's phenomen dalam batas normal. Pada pasien dilakukan ini prosedur repair ptosis dengan teknik frontalis suspension dengan fascia lata.

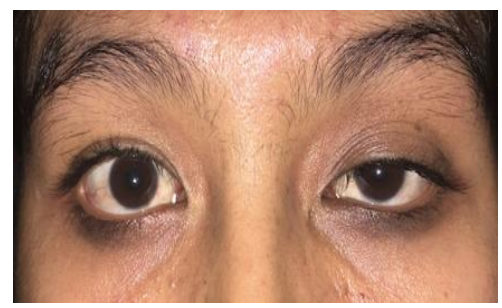

Gambar 1. Ptosis kongenital pada posisi primer

Prosedur frontalis suspension dengan fascia lata dilakukan dengan membebaskan dan mengambil fascia lata dari otot pada daerah sekitar $10 \mathrm{~cm}$ diatas suprakondilar lateral dengan ukuran $30 \times 15 \mathrm{~mm}$ dan kemudian direndam dalam cairan fisiologis. Pada palpebra, dilakukan insisi di daerah eyelid crease dan insisi di daerah frontalis. Melalui kedua insisi tersebut dibentuk tunnel yang menghubungkan palpebra hingga ke frontalis dan kemudian fascia lata dimasukkan ke dalam tunnel dan dijahitkan ke kulit dan tarsus serta dijahitkan di daerah frontalis.

Follow up pasien post operasi dilakukan pada hari pertama, setelah 1 bulan, dan setelah 3 bulan (Tabel 5).

Pada follow up hari pertama, palpebra mata kiri edem dan hechting palpebra dalam kondisi baik. MRD1 mata kiri $2 \mathrm{~mm}$ dan FPV $7 \mathrm{~mm}$. Selain itu, ditemukan lagoftalmus sebesar $2 \mathrm{~mm}$ (Gambar 2). Kondisi ini berkaitan dengan palpebra yang masih edem. Pasien diperbolehkan untuk rawat jalan dan diberikan obat antibiotik topikal dan analgetik oral. 

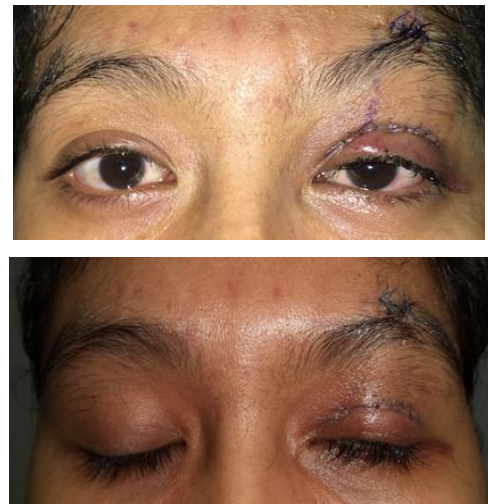

Gambar 2. Follow up hari 1 post operasi

Satu bulan post operasi, didapatkan peningkatan MRD 1 menjadi $3 \mathrm{~mm}$ sehingga FPV mata kiri meningkat menjadi $8 \mathrm{~mm}$. Edem palpebra sudah mulai berkurang. Lagoftalmus didapatkan sebesar $1 \mathrm{~mm}$ (Gambar 3).
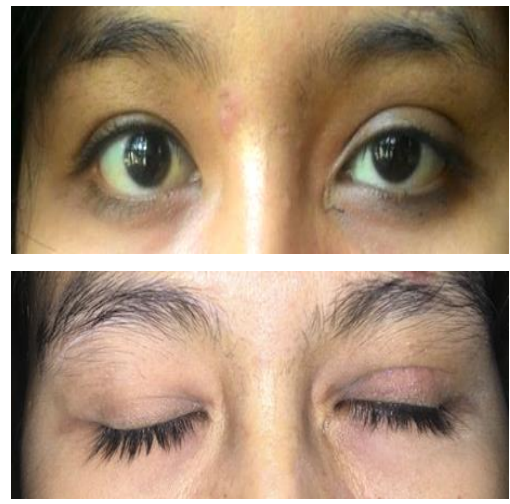

Gambar 3. Follow up 1 bulan post operasi

Pada follow up 3 bulan post operasi, MRD1 mata kiri meningkat menjadi $4 \mathrm{~mm}$ sehingga FPV menjadi $9 \mathrm{~mm}$. Kondisi ini memperkecil asimetrisitas kedua mata, dimana mata kanan memiliki FPV sebesar $11 \mathrm{~mm}$ (Gambar 4). Lagoftalmus masih ditemukan sebesar $1 \mathrm{~mm}$.
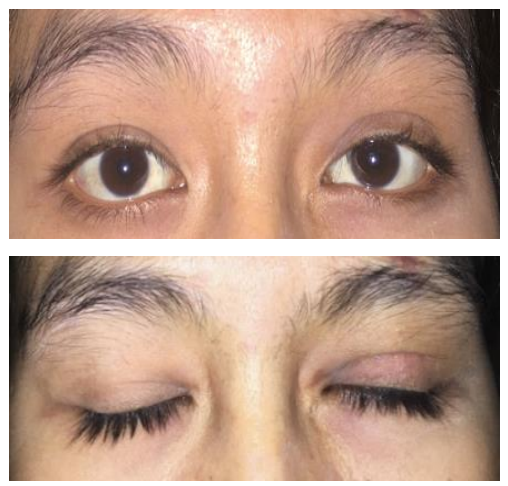

Gambar 4. Follow up 3 bulan post operasi

\section{PEMBAHASAN}

Berdasarkan onset, ptosis diklasifikasikan menjadi ptosis kongenital dan didapat. Ptosis kongenital adalah ptosis yang muncul saat lahir atau dalam tahun pertama kehidupan, sedangkan ptosis didapat adalah ptosis yang muncul di atas usia 1 tahun. ${ }^{2,3}$

Etiologi ptosis sangat bervariasi dan ptosis dapat merupakan tanda dari suatu penyakit, oleh karena itu sebelum diputuskan manajemen yang akan dipilih untuk repair ptosis, maka penting untuk menentukan etiologi ptosis. Ptosis dapat diklasifikasikan berdasarkan penyebabnya menjadi miogenik (akibat kelainan otot levator palpebra), aponeurosis (akibat defek pada levator aponeurosis atau pada perlekatan aponeurosis ke tarsus), neurogenik (akibat kelainan persarafan otot levator palpebra atau otot Muller), mekanik (akibat efek mekanik dari adhesi massa pada forniks konjungtiva superior atau massa pada palpebra superior) dan traumatik. Jenis ptosis yang paling sering ditemukan adalah ptosis miogenik kongenital dan ptosis apeunorotik didapat. ${ }^{3,4}$

Ptosis kongenital biasanya disebabkan oleh faktor miogenik akibat disgenesis atau kelainan pembentukan otot levator. Serat otot levator yang normal digantikan oleh jaringan fibrosa atau adiposa sehingga menggangu fungsi otot levator untuk kontraksi dan relaksasi. Oleh karena itu, pada pemeriksaan ptosis kongenital akibat kelainan pembentuk otot levator biasanya ditemukan fungsi levator yang buruk, lid lag, dan kadang dapat disertai dengan lagoftalmus. Eyelid crease biasanya tidak terbentuk sempurna atau bahkan tidak terbentuk sama sekali. Ptosis miogenik didapat jarang terjadi dan sering disebabkan oleh kelainan otot yang difus atau terlokalisir seperti distrofi muskular, chronic progressive external ophthalmoplegia, miastenia gravis, dan distrofi okulofaringeal. 1,2

Berdasarkan anamnesa, pada pasien ini didapatkan riwayat kelopak mata kiri turun sejak lahir, tanpa adanya riwayat trauma maupun riwayat operasi sebelumnya. Penurunan kelopak mata kiri dirasakan sama sepanjang waktu dan tidak disertai dengan keluhan penglihatan kabur ataupun penglihatan ganda. Anamnesis mengenai onset penyakit biasanya 
dapat membantu membedakan ptosis kongenital dari ptosis didapat. Riwayat keluarga, riwayat operasi okular atau palpebra sebelumnya, faktor predisposisi seperti trauma, apakah terjadi perburukan ptosis sepanjang hari, apakah terdapat gejala penyerta seperti diplopia, kelemahan otot, dan jaw-winking penting untuk diketahui. ${ }^{4,5}$

Pemeriksaan oftamologi umum yang penting dilakukan pada pasien ptosis antara lain pemeriksaan tajam penglihatan, gerakan bola mata, posisi alis mata, dan refleks cahaya pupil. Pemeriksaan kelainan refraksi, terutama pada ptosis kongenital, diperlukan untuk mengidentifikasi adanya ambliopia akibat anisometropia, strabismus, atau oklusi pupil pada mata ptosis. Ambliopia terjadi pada setidaknya $20 \%$ pasien dengan ptosis kongenital. ${ }^{1}$ Pada pasien ini, didapatkan tajam penglihatan normal (5/5), gerakan bola mata yang bebas ke segala arah, dan refleks cahaya pupil langsung dan tidak langsung normal pada kedua mata. ${ }^{5,6}$

Pengukuran yang penting untuk evaluasi ptosis adalah fisura palpebra vertikal (FPV), margin reflex distance (MRD), posisi eyelid crease superior, fungsi levator, bell's phenomenon, lid lag dan margin limbal distance (MLD). ${ }^{5,6}$

Pemeriksaan MRD1 digunakan untuk menilai posisi palpebra superior. Pemeriksaan dilakukan dengan cara mengukur jarak dari margo palpebra superior ke refleks cahaya kornea pada posisi primer. MRD1 normalnya adalah 4-5 mm. MRD1 bernilai positif jika palpebra superior berada diatas refleks cahaya kornea dan negatif jika menutupi refleks cahaya kornea. MRD2 merupakan jarak reflek cahaya kornea dengan margo palpebra inferior pada posisi primer, normalnya $5 \mathrm{~mm}$. Jumlah MRD1 dan MRD2 sama dengan FPV (gambar 5)., ${ }^{4,5}$ Nilai FPV pada pasien ini adalah $11 \mathrm{~mm}$ pada mata kanan dan $7 \mathrm{~mm}$ pada mata kiri.

Derajat ptosis dapat ditentukan berdasarkan nilai MRD1. Derajat ptosis pada kasus unilateral merupakan selisih antara MRD1 mata yang ptosis dengan mata normal, yang dapat dibedakan menjadi ringan ( $2 \mathrm{~mm}$ atau kurang), sedang ( $3 \mathrm{~mm}$ ), dan berat (4 $\mathrm{mm}$ atau lebih). Pada ptosis bilateral, MRD1 dikurangi dengan nilai normal MRD1 (4-5 mm). ${ }^{1}$ Pada pasien ini didapatkan nilai MRD 1 mata kanan normal
(5 mm), sedangkan MRD 1 mata kiri adalah $2 \mathrm{~mm}$ sehingga berdasarkan selisih MRD 1 pada mata kanan dan kiri pasien didapatkan ptosis derajat sedang $(3 \mathrm{~mm}){ }^{6}$

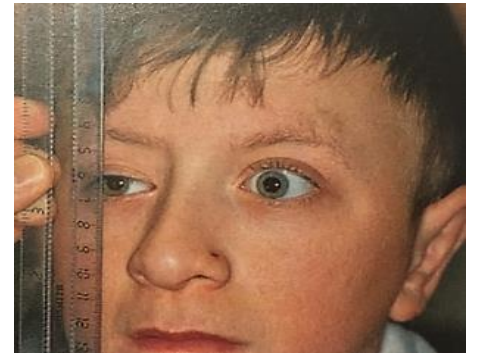

Gambar 5. Pemeriksaan MRD1 dan MRD2 pada ptosis. ${ }^{4}$

Pemeriksaan fungsi levator palpebra merupakan pemeriksaan yang sangat penting dalam evaluasi pasien dengan ptosis. Pemeriksaan ini dilakukan dengan mengukur posisi margo palpebra superior dari saat melihat ke bawah kemudian melihat ke atas secara maksimal. Otot frontalis dipastikan tidak membantu elevasi palpebra superior, yaitu dengan menekan alis pasien menggunakan jari jempol pemeriksa (gambar 6). Fungsi levator yang baik adalah 9-18 $\mathrm{mm}$, sedang apabila fungsi levator palpebra 5-7 $\mathrm{mm}$, dan buruk apabila $4 \mathrm{~mm}$ atau kurang. Pasien dengan ptosis kongenital biasanya memiliki fungsi levator yang buruk, seperti yang didapatkan pada pasien ini dimana fungsi levator palpebra mata kiri adalah $4 \mathrm{~mm}{ }^{6,7}$
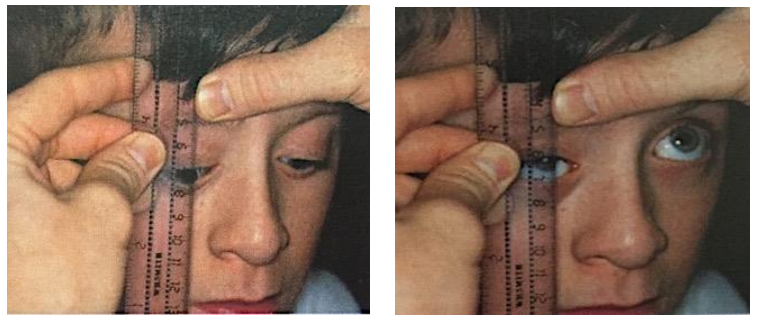

Gambar 6. Pemeriksaan fungsi levator. ${ }^{4}$

Fungsi levator yang buruk pada pada pasien ini juga tidak ditemukan eyelid crease pada mata kiri. Tinggi eyelid crease dari margo superior perlu dinilai karena eyelid crease dibentuk oleh insersi dari seratserat otot levator palpebra melewati septum orbita menuju otot orbikularis pretarsal hingga ke kulit. Posisi eyelid crease dinilai dengan mengukur jarak antara 
lipatan kulit palpebra superior dengan margo superior pada saat melihat ke bawah. Nilai normal ras kaukasia adalah 8-9 $\mathrm{mm}$ pada pria dan 9-11 $\mathrm{mm}$ pada wanita, sedangkan pada orang Asia tinggi eyelid crease biasany lebih rendah (4-6 mm pada pria dan 6-8 $\mathrm{mm}$ pada wanita). Tidak adanya eyelid crease mengindikasikan fungsi levator yang buruk, sedangkan posisi eyelid crease yang tinggi menunjukkan suatu defek aponeurotik. ${ }^{4,5}$

Pemeriksaan bell's phenomenon juga penting dilakukan dalam evaluasi ptosis. Pemeriksaan ini terutama diperlukan dalam mempertimbangkan operasi ptosis yang akan dilakukan, karena tidak adanya bell's phenomenon akan meningkatkan resiko eksposure kornea post operatif. ${ }^{1,2}$ Pada pasien ini, Bell's phenomenon pada kedua mata normal, dimana pemeriksaan dilakukan dengan menginstruksikan pasien untuk menutup mata dan kemudian pemeriksa mencoba membuka kelopak mata secara paksa, normalnya bola mata akan bergulir ke atas.

Posisi palpebra saat melihat kebawah juga dinilai untuk menentukan adanya lid lag. Lid lag menunjukkan ketidakmampuan otot levator palpebra untuk melakukan relaksasi, karena terdapat fibrosis pada otot levator palpebra. Sebaliknya, posisi palpebra superior yang lebih rendah saat melihat ke bawah dibandingkan dengan mata normal biasanya ditemukan pada pasien dengan ptosis aponeurotik. ${ }^{6,7}$

Prosedur repair ptosis bertujuan untuk menatalaksana kondisi yang melatar-belakanginya. Secara umum, prosedur repair ptosis terdiri dari 3 kategori; levator advancement eksterna (transkutan), reseksi otot levator/tarsus/Muller interna (transkojungtiva), dan frontalis suspension. Derajat, jenis ptosis, dan fungsi levator palpebra merupakan faktor penting dalam mempertimbangkan jenis prosedur yang akan dilakukan. 3,4 $^{3,4}$

Prosedur yang dipilih pada pasien ini adalah frontalis suspension. Prosedur frontalis suspension merupakan pilihan utama pada ptosis kongenital dengan fungsi levator yang buruk. Tujuan dari frontalis suspension adalah mentransfer aksi otot frontalis secara langsung untuk elevasi palpebra. Prosedur ini dapat dilakukan dengan menggunakan material suspensi autogen (fascia lata) maupun non-autogen (banked fascia lata, polypropylene, silicone tubing, atau vicryl/polypropylene mesh). ${ }^{8,9}$

Fascia lata merupakan pilihan utama untuk frontalis suspension pada ptosis kongenital, karena memiliki efek jangka panjang yang baik dalam membantu elevasi palpebra dan komplikasi yang minimal bila dibandingkan dengan material nonautogen. Sekitar 93\% pasien ptosis kongenital dengan fungsi levator yang buruk menunjukkan hasil yang baik secara kosmetik maupun fungsional dengan menggunakan fascia lata dibandingkan dengan material non-autogen. ${ }^{9,10}$

Pada kondisi tertentu dimana fascia lata tidak bisa digunakan, seperti pada anak dibawah usia 3 tahun namun dengan ptosis yang menyebabkan ambliopia, pada pasien usia lebih dari 60 tahun terutama dengan penyakit sistemik, dan pada pasien dengan miopati progresif dapat digunakan material non-autogen. Namun, material non-autogen ini biasanya memiliki kekurangan seperti berpotensi untuk menyebabkan terjadinya infeksi, ekstrusi, kerusakan, atau granuloma korpus alienum. ${ }^{6,7}$

Banked fascia lata merupakan fascia lata yang disimpan di bank jaringan dan biasanya digunakan pada pasien dengan usia kurang dari 3 tahun yang belum bisa untuk dilakukan pengambilan fascia lata. Silikon dapat digunakan pada pasien dengan distrofi otot, karena pada kondisi ini biasanya lagoftalmus tidak terlalu berat. Salah satu keuntungan penggunaan silikon adalah elastisitasnya yang memungkinkan penutupan palpebra secara sempurna dan tinggi fisura palpebra yang sesuai. Polypropylene merupakan material yang secara biologis paling tidak menimbulkan reaksi jaringan, sehingga mudah dalam pemasangan dan pengangkatan. Namun akibat strukturnya yang berpori, material ini dapat menjadi tempat penumpukan bakteri sehingga dapat menyebabkan terjadinya infeksi. 7,8

Material suspensi yang digunakan pada pasien ini adalah fascia lata autogen. Jaringan fascia lata diambil dari paha bagian lateral melalui insisi $3 \mathrm{~cm}$ pada daerah yang sejajar dengan garis imajiner yang menghubungkan kaput fibula dengan spina iliaca anterior superior dan sekitar $10 \mathrm{~cm}$ diatas kondilus lateral (gambar 7)..$^{10,11}$ 


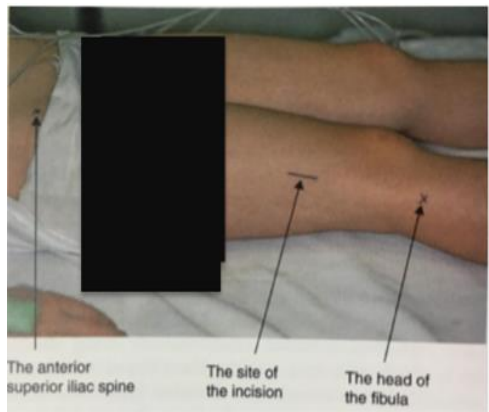

Gambar 7. Lokasi pengambilan fascia lata. ${ }^{4}$

Insisi kemudian diperdalam sampai ditemukan fascia lata yang tampak berupa jaringan berwarna putih mengkilat yang paralel dengan aksis kaki. Fascia lata dibebaskan dari jaringan disekitarnya dan kemudian dipotong dengan ukuran $30 \mathrm{~mm} \times 15 \mathrm{~mm}$ (gambar 8). Fascia lata kemudian dibersihkan dari lemak yang terbawa dan disimpan dalam cairan salin sampai siap untuk digunakan. Luka kemudian ditutup dengan jahit subkutan menggunakan vicryl 4/0 dan jahit kulit dengan prolene $4 / 0^{4,5}$

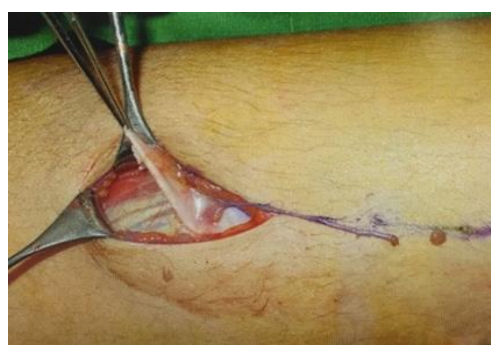

Gambar 8. Fascia lata. ${ }^{2}$

Beberapa teknik yang digunakan pada prosedur frontalis suspension antara lain single loop/strand, Fox Pentagon, dan Crawford double triangle (Gambar 9). ${ }^{2}$ Fox pentagon merupakan teknik yang cukup sederhana dan biasanya lebih dipilih pada frontalis suspension dengan material non-autogen. Teknik Crawford double triangle memiliki kontrol palpebra yang baik dan biasanya digunakan pada frontalis suspension dengan fascia lata autogen. Teknik ini merupakan salah satu teknik yang paling banyak digunakan dan dapat dilakukan pada pasien anak maupun dewasa. ${ }^{12}$

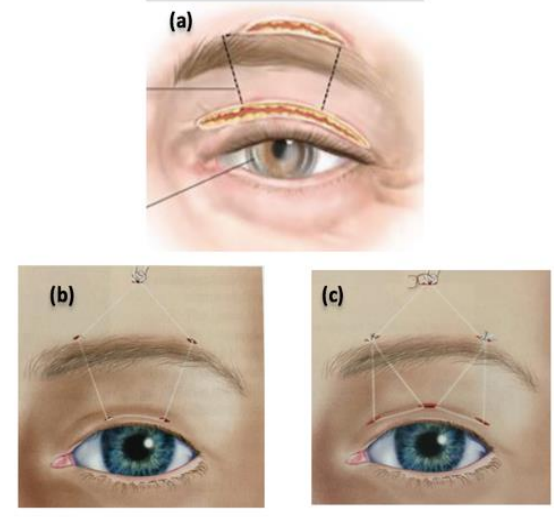

Gambar 9. Teknik single loop (a), Fox Pentagon (b), dan Crawford double triangle (c). ${ }^{4}$

Pada pasien ini teknik frontalis suspension yang digunakan adalah single loop/ strand. Prosedur dimulai dengan menentukan daerah insisi palpebra superior terlebih dahulu dengan menggunakan marker. Insisi palpebra superior dibuat sejajar dengan eyelid crease pada mata normal, pada pasien ini didapatkan tinggi eyelid crease pada mata yang normal adalah $7 \mathrm{~mm}$ di atas margo palpebra superior bagian sentral, insisi kemudian diperdalam sampai tarsus. ${ }^{4}$ Insisi sepanjang $15 \mathrm{~mm}$ dibuat pada daerah frontalis di bagian atas alis sekitar $30 \mathrm{~mm}$ diatas insisi palpebra superior. Selanjutnya, insisi daerah frontalis dan insisi palpebra superior tersebut dihubungkan melalui tunnel sub-orbikularis. ${ }^{12}$

Jaringan fascia lata kemudian dimasukkan ke dalam insisi palpebra superior dan kemudian dijahitkan ke tarsus dengan vycril 6/0. Fascia lata dimasukkan ke dalam tunnel sub-orbikularis atau jalur yang menghubungkan insisi palpebra superior dan insisi pada daerah frontalis. ${ }^{11}$ Eyelid crease selanjutnya dibentuk dengan menutup luka insisi palpebra superior dengan menjahit kulit sampai ke tarsus dan fascia lata. Sebelum menjahitkan fascia lata ke otot frontalis pada kasus unilateral, tinggi palpebra superior disesuaikan atau disejajarkan dengan tinggi palpebra mata yang normal, sedangkan pada kasus bilateral palpebra diangkat hingga $1 \mathrm{~mm}$ di bawah limbus superior. ${ }^{13}$ 
Komplikasi yang sering terjadi setelah prosedur frontalis suspension adalah lagoftalmus, undercorrection, overcorrection, dan asimetris secara kosmetik, terutama pada ptosis unilateral. ${ }^{11,12}$ Ptosis unilateral dengan fungsi levator yang buruk merupakan kasus yang cukup sulit untuk ditalaksana. $\mathrm{Hal}$ ini disebabkan karena kemungkinan hasil akhir yang asimetris sehingga diperlukan. Beberapa peneliti menganjurkan untuk melakukan prosedur frontalis suspension secara bilateral pada ptosis unilateral untuk mendapatkan hasil yang simetris. ${ }^{14,15}$ Pada pasien ini, komplikasi post operatif yang ditemukan setelah follow up selama 3 bulan adalah lagoftalmus (1 $\mathrm{mm}$ ). Outcome yang cukup baik didapatkan dengan MRD1 mata kiri $4 \mathrm{~mm}$ (FPV $9 \mathrm{~mm}$ ) yang secara kometik dapat diterima oleh pasien.

\section{SIMPULAN}

Ptosis kongenital unilateral merupakan kasus yang cukup sulit untuk ditatalaksana. $\mathrm{Hal}$ ini disebabkan karena outcome repair ptosis yang asimetris sehingga secara kosmetik tetap tidak dapat diterima oleh pasien meskipun secara fungsional terdapat perbaikan. Prosedur frontalis suspension dengan fascia lata dan dengan menggunakan teknik single loop cukup efektif dalam meberikan outcome yang dapat diterima oleh pasien dengan ptosis kongenital unilateral.

\section{SARAN}

Frontalis suspension dengan fascia lata disarankan sebagai pilihan utama untuk pasien ptosis dengan fungsi levator yang buruk, baik unilateral maupun bilateral.

\section{UCAPAN TERIMAKASIH}

Terimakasih kepada Ketua Program Studi IImu Kesehatan Mata Program Pendidikan Dokter Spesialis Fakultas Kedokteran Universitas Andalas dan Ketua Bagian IImu Kesehatan Mata RS Dr.M.Djamil Padang yang telah membantu dalam penulisan laporan kasus ini.

\section{DAFTAR PUSTAKA}

1. Cantor LB, Rapuano CJ, Cioffi GA. Orbit, eyelid, and lacrimal system. Singapore: American Academy of Ophthalomology; 2015.

2. Grover A, Bageja S. Oculoplastic and reconstructive surgery. Edisi ke-3. New Delhi: Jaypee; 2010.

3. Ahmad SM, Della Rocca RC. Blepharoptosis: evaluation, techniques, and complications. Facial Plastic Surgery. 2007;23(3): 203-15.

4. Leatherbrow B. Oculoplastic surgery. Edisi ke-2. London (UK): Informa Healthcare; 2011.

5. Edmonson BC, Wulc AE. Ptosis evaluation and management. ophthalmology clinics of North America. 2005;38(12):921-46.

6. Krishmakumar S. Clinical evaluation and management of ptosis. Clinical AECS Illumination. 2013;8(4):1-7.

7. Manners R. Ptosis. Dalam: Collin R, Rose G, editor (penyunting). Fundamental of clinical ophthalmology: plastic and orbital surgery. Malaysia: BMJ Books; 2010.hlm.32-40.

8. Frishberg B. Principle and technique of examination of the trigeminal nerve. Dalam: Miller R, Newman NJ, editor (penyunting). Walsh \& Hoyt's clinical neuro-ophthalmology. Edisi ke-6 New York: Lippincott Williams \& Wilkins; 2001. hlm. 285-330.

9. Dutton JJ, Gayre GS, Proia AD. Diagnostic atlas of common eyelids disease. New York: Elsevier; 2007.

10. Gonzalez MO, Durairaj VD. The history of ptosis surgery. Dalam: Cohen AJ, Weinberg DA, editor (penyunting). Evaluation and management of blepharoptosis. New York: Springer;2011.hlm.5-11.

11. Jafri HR, Rauf A, Qidwai N, Shaikh AR, Soomro FA, Dawood A. Frontalis suspension for unilateral ptosis with poor levator function. Pakistan Journal of Ophthalmology. 2013;29(1):3-7.

12. Allard FD, Durairaj VD. Current techniques in surgical correction of congenital ptosis. Middle East African Journal of Ophthalmology. 2010;17 (2): 129-33. 
13. Nasr HE, Essawy RAA, Ahmed RA, Soliman AZ. Fascia lata frontalis sling for treating congenital ptosis : anatomical and cosmetic outcomes in monotriangular versus bitriangular configuration. Medical Journal of Cairo University. 2012;80(2):203-9.

14. Ben Simon GJ, Macedo AA, Schwarcz RM, Wang DY, McCann JD, Goldberg RA. Frontalis Suspension for Upper Eyelid Ptosis: Evaluation of
Different Surgical Designs and Suture Material. American journal of ophthalmology. 2005;140(5): 877-85.

15.Kersten RC, Bernardini FP, Khouri L, Moin M, Roumeliotis AA, Kulwin DR. Unilateral frontalis sling for the surgical correction of unilateral poorfunction ptosis. Ophthalmic Plastic \& Reconstructive Surgery. 2005;21(6):412-6. 